\title{
Utilizing the Internet to Improve Student Learning in a First Course in Engineering Economy with Real-World Unsolved Problems in Collaboration with Industry
}

\author{
Janis P. Terpenny ${ }^{1}$, William G. Sullivan ${ }^{2}$, Harpreet $\operatorname{Singh}^{3}$, Kimberly Sward ${ }^{1}$ \\ University of Massachusetts, Amherst, $\mathrm{MA}^{1} /$ \\ Virginia Polytechnic Institute and State University, Blacksburg, $\mathrm{VA}^{2} /$ \\ Alstom Power, Windsor, $\mathbf{C T}^{3}$
}

\begin{abstract}
This paper reports on results of an experiment to investigate whether technology and the Internet facilitate student learning of Engineering Economy through real world problems in collaboration with industry. An overview of the organization and administration of the collaborative projects is presented. Learning aids and Internet tools are included in this discussion. Assessment results of student performance and perception are also presented. It was found using a bootstrap sample, at a significance level of 0.05 , that the grade point average (GPA) of students working on projects in collaboration with industry administered through a variety of tools over the Internet (Experimental Group) was higher than those receiving only traditional classroom style lecture (Control Group). Overall, we conclude that the Internet is an effective and efficient medium for incorporating industry based projects into the curriculum, leading to greater student proficiency with course material and the fundamental concepts of Engineering Economy as applied to the real world. Conclusions and future plans are also provided.
\end{abstract}

\section{Introduction}

The inclusion of real-world industry provided problems in undergraduate education reinforces concepts and improves learning in ways not available through traditional methods of lecture or predefined case problems. Students develop problem solving skills, project management skills, communication and teaming skills, and a sense of professionalism through such experiences. For Engineering Economy in particular, real-world problems convey the difficulties of data gathering, assumption making, problem formulation and the importance of economic analysis in decision making. While the potential benefits to students, faculty, and industry partners may be great from real-world problems and collaboration, the investment of time and effort in creating and running such projects can be significant. Reflecting on limited resources and time of all participants, one must question whether student learning is sufficiently improved to justify the significant effort required for offering such experiences in courses other than senior design courses, the most typical course for real-world industry based projects. Further, if learning can be improved, are there methods or technologies that could possibly reduce the logistics and improve the experience for all participants? 
The rapid growth and affordability of Internet technology has provided immense opportunity for educational institutions to expand, enhance, and perhaps replace traditional classroom teaching. Web-based instruction, or the virtual classroom as it is sometimes known, is an environment that can potentially facilitate collaborative learning among students, between students and instructors, among instructors, and between an entire class and wider academic and non-academic communities $^{1,2}$. It can also be used to support independent and active learning techniques and self-paced instruction ${ }^{3}$. While the Internet offers many new potential benefits, exactly how and to what degree the Internet is effective in education is an important question to address. This is especially true in light of recent studies that show classroom instruction cannot be effectively replaced solely by a virtual classroom environment ${ }^{4}$. When used as a supplement to the classroom however, the Internet has been shown to be an effective medium for enabling new approaches to education. It can help to define an interactive learning environment with new opportunities for students to experience distributed and cross-functional teams, increased personal attention, and collaboration with industry for teams as well as individual students ${ }^{4-6}$.

This paper reports on results of an experiment to investigate whether technology and the Internet facilitate student learning of Engineering Economy through real-world problems in collaboration with industry. These results are part of a larger project whose purpose was to define a virtual classroom for teaching the economics of engineering design, including on-line course modules, practice quizzes, and administrative support tools in addition to the industry collaborative projects ${ }^{8-9}$. It was found that, by far, the industry-based projects had the greatest significance on increasing student learning of course concepts, problem solving, and collaboration and communication skills as well as improving overall student satisfaction. The sections that follow provide a description of the organization and administration of the collaborative projects, learning aids and Internet-based tools developed to support the projects and collaboration, highlights of specific industry projects, and results and evaluation of student performance. Conclusions and future plans are also provided.

\section{Organization and Administration of Collaborative Projects}

Two universities, Virginia Tech and the University of Massachusetts Amherst (UMass), and several engineers at General Electric (GE) Industrial Systems, participated in the industry-based projects. Faculty at both universities worked cooperatively and with industry partners to define, organize, and administer the projects. Although projects come primarily from industry partners, faculty aid in the selection of appropriate projects and edit problem statements with student capabilities in mind. Once launched, industry partners are the main contacts for queries from students regarding the assumptions and general details of projects. Faculty are responsible for providing milestones to students, meeting with student teams to aid progress, responding to teaming issues, suggesting strategies for data collection and assumption making, general encouragement, and for grading interim and final reports. Instructors and industry partners may suggest tools and methods from course topics that could be used to approach problems when not apparent from the problem statement and description. Student teams consisted of 3-4 members with one of these members, selected from within the group, serving as the team leader 
responsible for overall management of the project as well as for meeting specific deadlines for the completion of the project.

Summarized in outline form, the guidelines shown below provide student teams with the needed framework to succeed with the industry based projects. Word phrases underlined are links to additional resources on the industry projects web page. For instance, Currently Available links to the page where current industry project descriptions reside. Project Teams is a link to the page where team memberships and contact information is found. Project Planning \& Management links to resources that instruct students on how to plan, manage and succeed as a team. Due Dates links to important dates for project teams, somewhat different for each university based on instructor preferences of desired milestones and timing. Project Reports provides guidance on good report writing and specific requirements.

\section{- Form student project teams}

The formation of teams will vary from self-selected to instructor assigned as deemed appropriate by the instructor.

- Select an industrial problem from those Currently Available.

Rank order and submit your top 2 choices to your instructor.

The instructor will make every effort to assign problems to teams according to their preference. Refer to Project Teams for membership and contact information of team members.

- Make use of the Economic Principles and the Engineering Economic Analysis Procedure outlined by your instructor and/or textbook to guide your work on the project.

Describe the problem

Develop and describe the possible alternatives

Collect any relevant data that you will need in your analysis

State all assumptions explicitly

Perform the analysis

Iterate

Perform sensitivity analysis if appropriate

Make your recommendations etc.

- Apply any and all techniques and tools that you feel are appropriate to your problem

Examples include but are not limited to: work (cost) break down, cost estimating, cash flow diagramming, equivalent worth methods, payback period methods, learning curves, sensitivity, QFD, etc.

- Make use of any and all sources of information available Industrial contact listed with problem may be contacted via e-mail. 
Depending upon the location and availability of the contact, you may suggest visiting your contact personally.

Check back for updates to the virtual classroom web pages frequently. Additional resources provided by industrial contacts will be posted to the page as they become available.

Do not hesitate to be resourceful. Information can be found from publications (literature), on the web, contacting suppliers/vendors directly, etc.

- Meet frequently as a project team (whether co-located or in a distrbuted manner) Divide project tasks and roles among team members (Who is responsible for what? Be specific, responsible, accountable to your team)

Develop a detailed project plan (milestones, tasks, dates, etc.)

Document the project plan on a Gantt and/or Pert Chart - include this in any required progress reports

Refer to Project Planning \& Management

\section{- Reports and due dates:}

Depending upon your instructor, you may be required to submit a project plan and periodic progress reports.

Check Due Dates to clarify the particular requirements of your class.

At the end of your project work, each team should submit 2 hard copies of their final report to the instructor. Your instructor may also request electronic copies of your report and final presentation.

One of these copies is for the instructor and grading. The second copy is for the participating industrial partner so that they can benefit from your efforts.

Refer to Project Reports for report format requirements.

Generally, the collaborative projects begin following a kick-off guest lecture from industry partners. Based on their initial impressions of the diverse problem choices presented (typically 4 different problems) and added review of on-line descriptions, students make a problem selection and group themselves into teams. We find personal contact from industry helps motivate and interest students. Typically, 1-2 additional help sessions or guest lectures from industry partners take place during the course of the project period. Guest lectures are digitally recorded and then placed on the web page for review by students who attended the lecture as well as student groups who may be located remotely from the university hosting the guest lectures. In some cases, faculty from one university have guest lectured at the other university on a special topic, such as project planning and management. Again, guest lectures are recorded and placed on the common web page for sharing with the larger community.

After selecting problems and team formation, each group provides a statement that reinterprets the problem in their own words, and states in general how they intend to approach the problem. In subsequent weeks, one page progress reports are submitted (optionally, depending upon the faculty preferences) identifying what tasks will be performed, and who on each team will be

Proceedings of the 2002 American Society for Engineering Education Annual Conference \& Exposition Copyright $\mathbb{0}$ 2002, American Society for Engineering Education 
doing each task. Reports should indicate what has already been accomplished and what remains to be done. Problem areas should be noted, in particular difficulties in communication and in obtaining data. Although left to the discretion of the teams, students generally meet at least once per week early in the project, more frequently with progress and near due dates. Students communicate with industry partners as needed through e-mail, message board, phone, or other methods that they and their contacts deem appropriate. Most students take frequent advantage of the freely provided support from outside collaborators.

By the conclusion of the industry based term projects, students are required to submit a detailed report of professional quality for grading and submission to industry partners, all tools and analyses developed and (depending on time available, class size, and faculty preferences) a formal presentation of their work. The following outline is suggested for project reports:

- Cover Page (include a minimum of: title of problem, university name and course number, team member names, date )

- Table of Contents

- Executive Summary (1 page overview of your problem, what you did, the benefits)

- Introduction include a brief background and motivation for your paper and work.

- Specific purpose and objectives you tackled

- Scope and assumptions of the solution procedure

- Approach and methodology used (include alternatives examined, mathematical formulations if appropriate).

- Results (what did you find)

- Recommendations and Conclusions

- Areas for further development and/or study that you would suggest or would do if time allowed

- Lessons Learned (required)

- Bibliography - Give credit to all sources you have used (data, published materials, interviews, internet sources, etc.).

- Appendices (optional - supporting materials that might be useful to the reader)

This is a very traditional report format that students are likely to encounter again in the future. Surprisingly, many sophomore and junior level students are still gaining an understanding and skill with this format. Our favorite item, Lessons Learned, is a bit different and generally pulls a wide array of comments from student groups. In some instances, lessons are problem specific. Most often, lessons learned include a new found appreciation of data gathering, assumption making, the challenges of teaming, and the realization that Engineering Economy plays a very important role in industry projects and decision making. 


\section{Learning Aids and Internet Tools for Projects and Collaboration}

As mentioned previously, the projects in collaboration with industry are part of a larger effort to develop a virtual classroom for teaching the economics of engineering design. The industry projects portion of the virtual classroom can be selected from the main web page ${ }^{9}$ or accessed directly ${ }^{10}$. Figure 1 provides a screen capture of the industry projects home page. As shown, the largest area displayed, located on the right-hand side of the page, contains the topic currently selected. In the case of the initial visit to the industry projects homepage, objectives are displayed. The upper portion of the left-hand side of the page contains general selections for the larger Virtual Classroom. In the lower portion of the left-hand side of the page, are selections for materials that support the execution of the industry-based projects and facilitate communication and teaming among participants.

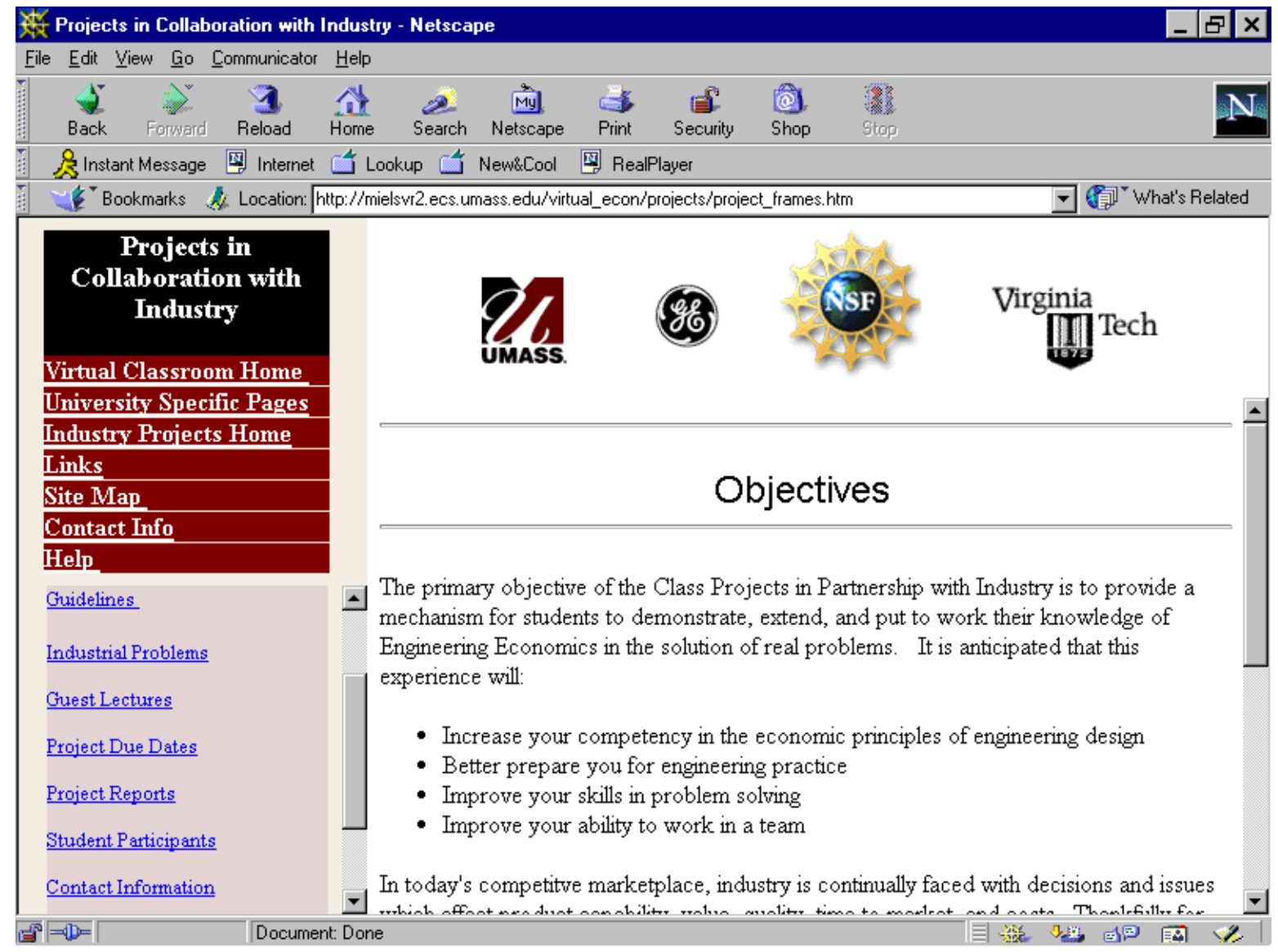

Figure 1. Projects in collaboration with industry web page. 
Briefly, selections for the industry projects web page include:

- Guidelines - provides an overview of the steps and requirements for successful student teams,

- Industrial Problems - where industry problem descriptions and additional supporting materials from industry are found,

- Guest Lectures - PowerPoint slides and digitally recorded audio/video files of industry and faculty guest lectures,

- Project Due Dates - key dates for project milestones, specific to each participating university,

- Project Reports - guidance on the outline and requirements for project reports,

- Student Participants - student contact information by team and location, and

- Contact Information - faculty contact information is found here. Industry contact information is found with Industry Problem statements since, potentially, each problem may have a unique contact person.

Primarily, student-industry and student-student interaction was implemented through the use of a message board and through e-mail contacts. The message board was implemented to provide an open forum for discussion for the industry-sponsored projects. Studies indicate that message boards significantly improve interaction and elevate the sense of community between class members in larger classes. This in turn improves the motivation levels, the quality of the work, and retention ${ }^{11}$. Students used the message board to post questions related to the industry problems. In response to this posting, an industry representative would receive an e-mail message alerting him to the posting for a timely response. Most often, questions were for problem clarification or to request guidance and data on specific topics.

The message board was implemented through DISCUS ${ }^{12}$, a system based in Perl-CGI. It enables the use of passwords, and restrictive powers within its system as well as customization features. Refer to Figure 2 for a sample of the message board.

\section{Highlights of Industry Projects}

This section provides brief highlights for four of the projects provided by General Electric (GE) Industrial Systems. Additional details for each project can be obtained from the projects in collaboration with industry web site ${ }^{10}$, a dynamic resource page that changes as industry partners provide additional clarifications and data. Problems provided by other industry partners, Pratt and Whitney for instance, are also available from the industry projects web page. 




Figure 2. Message board for projects in collaboration with industry.

Brief summaries of four real-world problems provided by GE follow.

- Increasing Profits by Finding "Best in Class" Suppliers. GE introduces many new products throughout the course of every fiscal year. Students were given information about the current cost of a particular subassembly and the number of units GE expected to sell per year. Students were given a $20 \%$ cost reduction target for the subassembly and were told to manage four steps of the new product introduction (NPI) project: supplier pool definition, supplier selection, supplier qualification, and part qualification.

- Minimizing the Number of New Parts Introduced Through Reuse of Existing Parts. The second project involved an enormous inventory control challenge where incidents of multiple functional equivalent parts denoted by different part numbers and/or different descriptions existed in a database. The students were asked to develop a model that would enable GE to predict the cost over a three-year period of having a certain allowable level of "extra" parts in the database.

- Balancing the Initial Cost of Ownership of a Power System with Efficiency, Reliablity, and Life Expectancy. The third project involved selecting the most cost effective type of transformers for a recently constructed industrial complex. The complex

Proceedings of the 2002 American Society for Engineering Education Annual Conference \& Exposition Copyright (C) 2002, American Society for Engineering Education 
needed to balance the initial cost of ownership with increased efficiency, reliability, and life expectancy of the power distribution transformers purchased. There was a critical need to validate cost, reliability, and longevity to insure the complex did not overpay initially or have to replace too many transformers too soon. The project extended over a 25-year study period.

- Optimizing Product Development Cost Through Off-Shore Outsourcing. The fourth project involved the possible out-sourcing of off-shore labor and facilities to develop and design new products. The objective of the project was to determine the best method to expand the GE design team to meet an expansion of a particular product line over the next five years. Students were charged with developing a proposed hiring and assignment plan for the entire five-year period that minimized cost while satisfying the demand expected for the design team.

It should be noted that all industry problems have been kept somewhat open-ended to allow student teams the freedom and flexibility to be creative in approach and appreciate the vague nature of real-world problem statements. Faculty and industry partners do not anticipate specific solutions to any problem and encourage creativity. As expected, the solutions of different teams for any one problem are usually quite different since assumptions, methods, and approaches employed in each case garner different results and insights into the problem.

\section{Results and Evaluation}

A summary of the results and evaluation of student performance and perception for the industrybased projects are presented in this section. The primary focus of our analysis has been students enrolled in the large lecture sections of Engineering Economy (ISE 2014) at Virginia Tech. This group is particularly interesting since offering industry-based projects, or projects of any sort, to large classes can be logistically challenging and costly. Again, the main question to address for such a large group is whether technology and the Internet can improve student learning in a first course in Engineering Economy with real-world unsolved problems in collaboration with industry.

Students were divided into two groups for the purpose of this analysis. The experimental group consisted of those students who took the projects in collaboration with industry and students who attended the conventional classroom without taking on the projects, the control group. The analysis that was performed to determine the effectiveness of the projects on learning was based on traditional performance measures of assessment including grades for course homework and examinations. In addition, in-class surveys ${ }^{13,14}$ were administered to gather student perception of their skills in problem solving and teaming and to evaluate web-based materials and their overall experience. 
The experimental and control groups at Virginia Tech were established according to lecture sections. The experimental group consisted of those students in the 8:00 am section while the control or conventional classroom consisted of students in the 10:00 am section. Both sections were taught by the same instructor and had the same tests and exams. Students had the choice of enrolling in either section and were allowed to switch from one section to the other at the beginning of the semester. Interestingly, little movement occurred from one section to the other, most probably due to schedules and little information about the projects at the outset of the semester. The grading methodology differed only in the fact that $15 \%$ of the final grade was based on the project for the experimental group. However, for the purposes of analysis, identical weights were used for tests, homework, and the final exam. In this manner, the projects were given no weight in comparing the final scores of the two groups.

The analysis was based on the student grade point performance with all grades adjusted to a 10point scale for consistency. Prior to finding differences that may be attributable to the experiment, possible differences in the two student populations were first assessed based on prior performance by comparing grade point performance of senior and junior level students. On a scale of $0-10$, the difference of the grade point performance (experimental-control) was 0.03 , obtained by 100 bootstrap samples with replacement 40 times (See Figure 3).

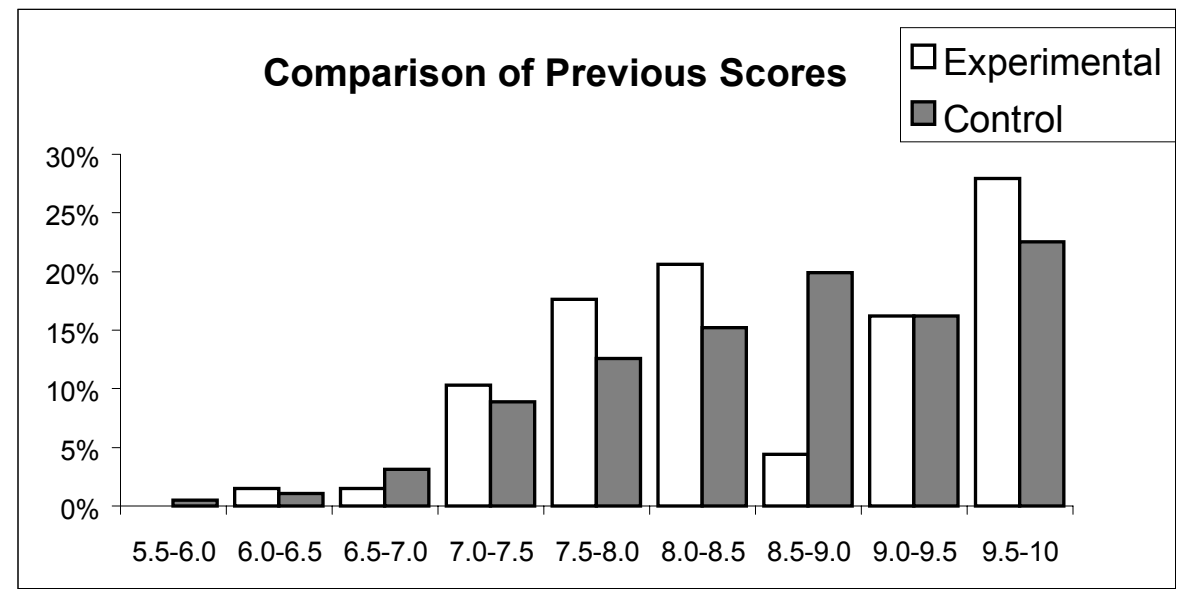

Figure 3. Comparison of previous scores.

A two-tailed t-test was then used to test for the difference between the final grades of the experimental section and the control section. This resulted in test statistics that were normal with the Anderson Darling Normality test result $\mathrm{p}>0.05$. The two-tailed t-test gave $\mathrm{p}=0$ for the 8:00 AM experimental section mean being greater than the 10:00 am control section mean by at least 0.03 (previous score difference) at a significance level of 0.05 . The test clearly indicates that the 8:00 am experimental group of students out performed the 10:00 am control group class. These results are summarized below in Figure 4 and Table 1. 


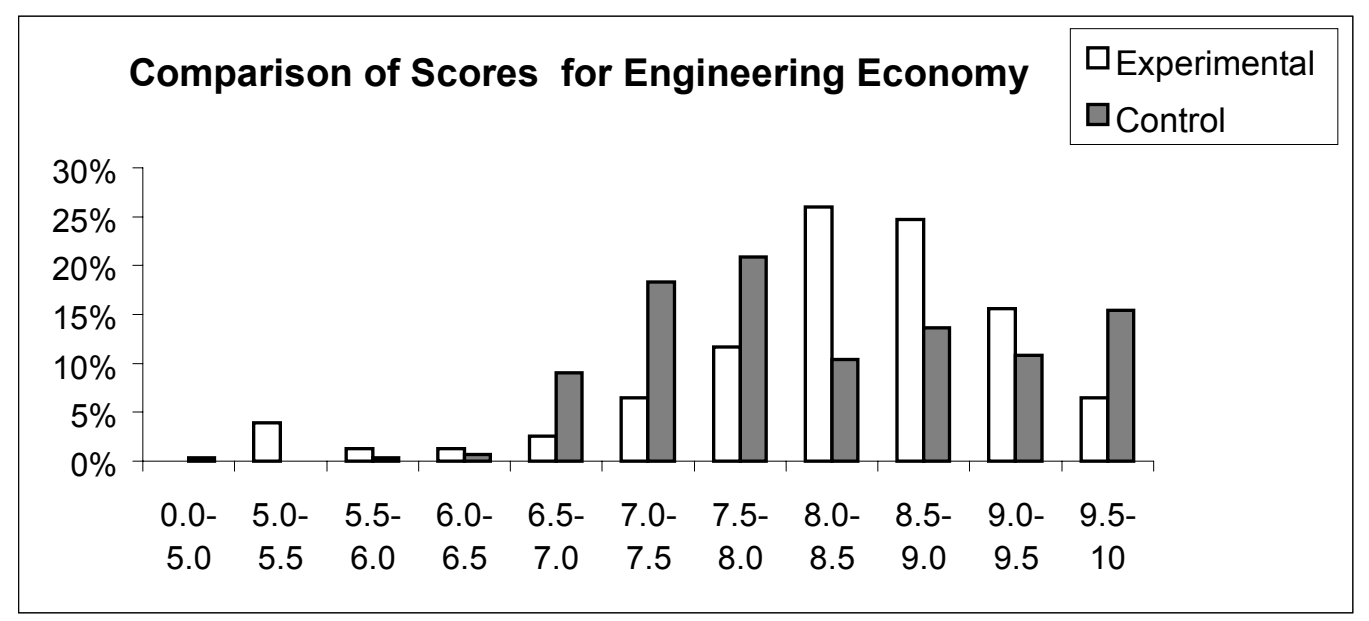

Figure 4. Comparison of scores for Engineering Economy.

Table 1. Bootstrap Statistics for Engineering Economy* (EE) and Senior Scores *(SS).

\begin{tabular}{|c|c|c|c|c|}
\hline Variable & Mean & $\begin{array}{c}\text { Standard } \\
\text { Deviation }\end{array}$ & SE Mean & $\begin{array}{c}\text { Anderson-Darling } \\
\text { Normality Test }\end{array}$ \\
\hline Experimental Group (SS*) & 8.824 & 0.167 & 0.016 & 0.425 \\
\hline Control Group (SS*) & 8.794 & 0.145 & 0.0146 & 0.496 \\
\hline Experimental Group (EE*) & 8.026 & 0.169 & 0.016 & 0.425 \\
\hline Control Group (EE*) & 7.726 & 0.148 & 0.014 & 0.583 \\
\hline
\end{tabular}

In addition to the comparison of actual scores of the experimental and control groups, predicted performance versus actual performance of each group was performed. Predicted performance was calculated based on a regression equation developed over several years of indicator data gathered from students taking Engineering Economy at Virginia Tech ${ }^{15-16}$. Student data used in this predictive equation include SAT scores, high school standing, current academic year (e.g., freshman, sophomore, etc.), and current grade point average (GPA). A bi-directional t-test was used to test for a difference between the predicted and actual final scores of the students in the experimental section. The t-test indicated a significant difference between the mean predicted scores. At alpha $=0.05$, the calculated $t$ value was 2.72 , which was greater than $t^{*}=1.96$. Thus, the hypothesis that there is no significant difference between predicted and actual final score means of students in the experimental group is rejected. We conclude that there is a significant difference between the predicted and actual final scores (predicted being greater than actual).

Overall, student comments were positive about the experience of working on projects with industry collaborators. Most students stated that they liked working on real-world problems and particularly enjoyed the collaboration with industry partners. We believe that having a "customer" to please, the industry contacts, played largely on student motivation. 
To gather anecdotal information concerning the experiment, a questionnaire was given to the students twice during the semester, first during the second week of classes prior to the start of the projects and again during the last week of the semester upon finishing the projects. Questions were grouped into four categories to discern student perception of 1) critical thinking skills, 2) technology awareness, 3) study skills, and 4) personal feelings. The actual questions appearing on the questionnaire are shown in Table 2. A total of 13 questions were asked of the students in the questionnaire. Students had to choose from five separate responses: Strongly Agree (SA), Agree (A), Disagree (D), Strongly Disagree (SD), and Not Applicable (NA). For each question, the desired response was intended to be Strongly Agree. In our opinion, a Strongly Agree response would indicate that the student had a favorable attitude and awareness of the four categories.

Table 2. Questions Appearing on Student Questionnaire

\begin{tabular}{l} 
Critical Thinking Questions \\
\hline \multicolumn{1}{|c|}{ This course helped me learn to work through a process to solve problems. } \\
\hline I would rate my problem solving skills as adequate. \\
\hline I would rate my ability to work in a team as adequate. \\
\hline \multicolumn{1}{|c|}{ Technology Awareness Questions } \\
\hline The technology used in this course was appropriate for performing the tasks required. \\
\hline $\begin{array}{l}\text { I would recommend that others take a course that uses electronic communication, such as electronic mail } \\
\text { or computer conferencing. }\end{array}$ \\
\hline $\begin{array}{l}\text { I would recommend that others take a course that provides an opportunity to author multimedia materials, } \\
\text { such as texts, course modules or presentations. }\end{array}$ \\
\hline \\
\hline This course taught me how to work in a team/group to complete a project. \\
\hline I planned specific study times for this course and stuck to the schedule. \\
\hline Assignments for this course helped me understand what will be expected of me as a professional. \\
\hline \multicolumn{1}{c|}{ Personal Feelings Questions } \\
\hline The instructor for this course returns graded assignments quickly. \\
\hline I looked forward to working on assignments for this course. \\
\hline This course did not conflict with my work and/or family responsibilities. \\
\hline I would recommend this course to others. \\
\hline
\end{tabular}

For the group of questions related to critical thinking skills and also for the technology awareness group of questions, there was a noticeable shift in responses from the first administration of the questionnaire at the beginning of the semester to the one at the end of the semester. For critical thinking, there was a small decrease in Agree responses (76\% to $73 \%$ ) from the beginning to the end of the semester, but a large increase in the Strongly Agree responses (12\% to 21\%) seen over the same timeframe. For technology awareness questions, there was again a small decrease in Agree responses (63\% to 61\%) over the period and a large increase in Strongly Agree responses $(10 \%$ to $17 \%)$. Overall, the total percentage of unfavorable responses for critical thinking as well as for the technology awareness groups of questions also decreased over the course of the 
semester. The percentage of each response for the Critical Thinking questions is given in Figure 5. Summary results for Technology Awareness are shown in Figure 6.

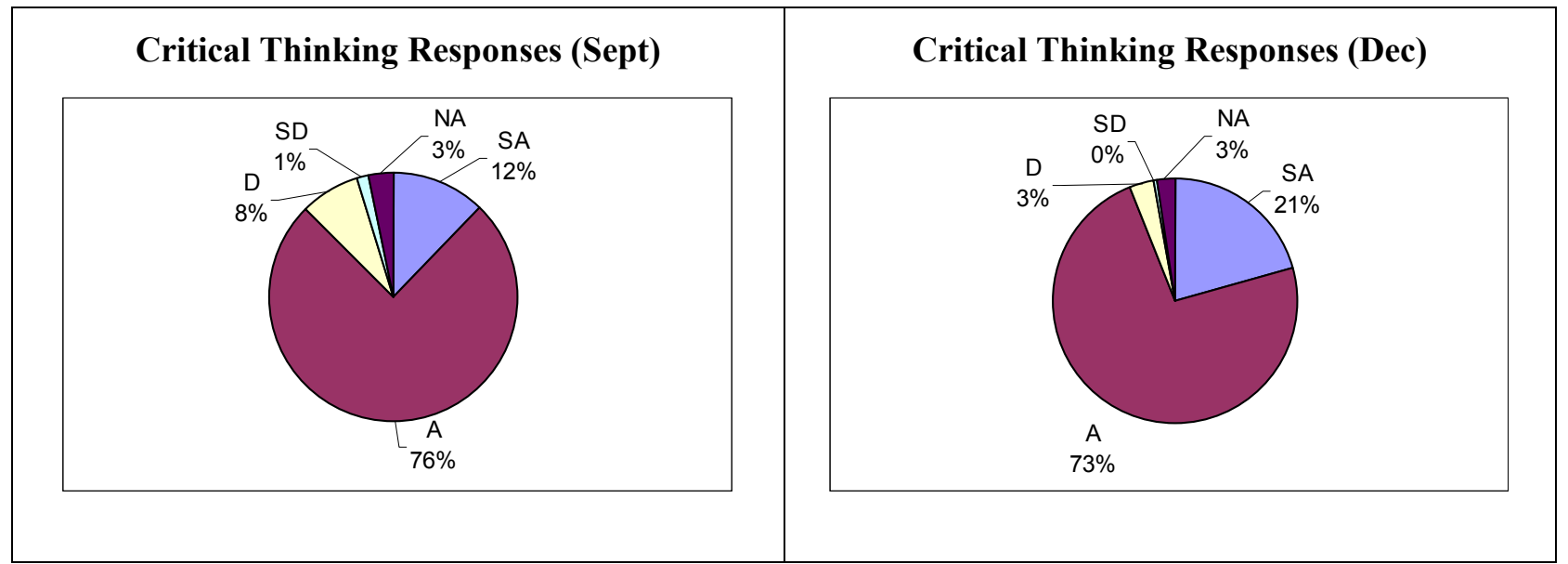

Figure 5. Responses to Critical Thinking Questions.

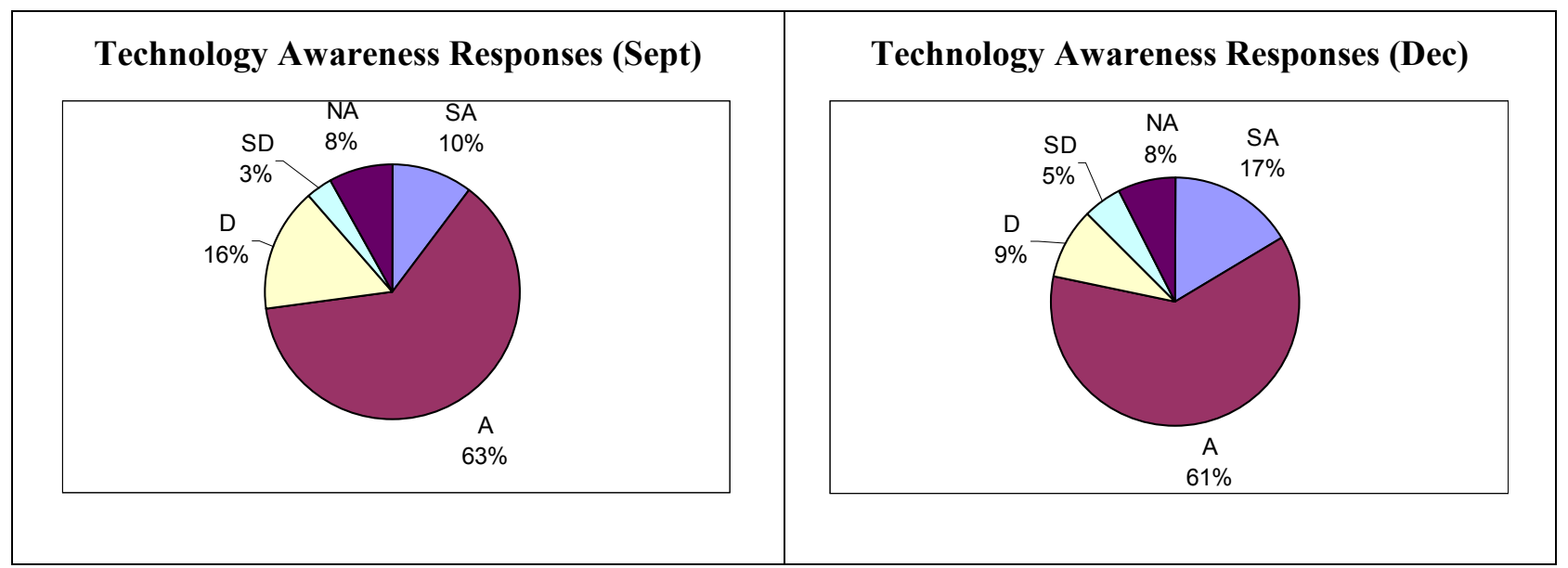

Figure 6. Responses to Technology Awareness Questions. 
Figure 7 shows results of Study Skills questions and shows very small increases of Agree and Strongly Agree responses (2\% and $1 \%$ respectively). Most disturbing about these results is the increase in unfavorable responses from September to December. Conjecturing on why this would be and analyzing this result would require additional study.

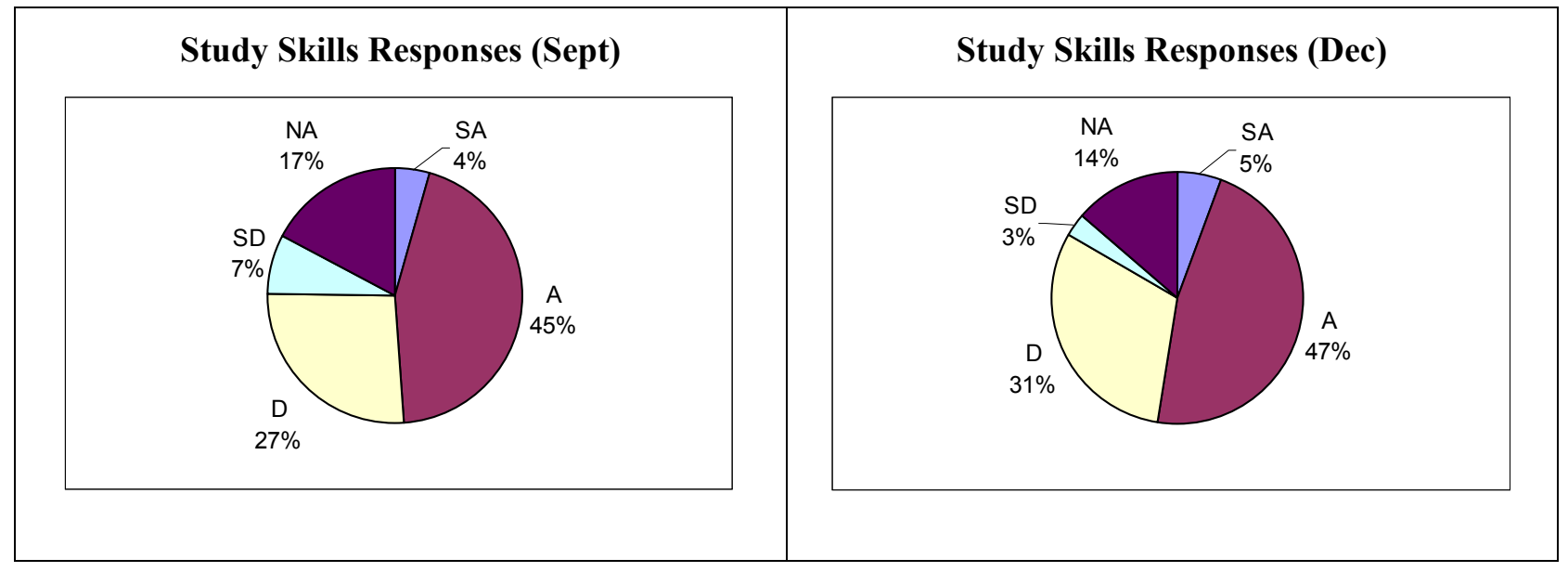

Figure 7. Responses to Study Skills Questions.

The response summary for Personal Feelings questions is given in Figure 8 and shows small increases in both Agree responses and Strongly Agree responses. Unfavorable responses virtually stayed the same throughout the semester.

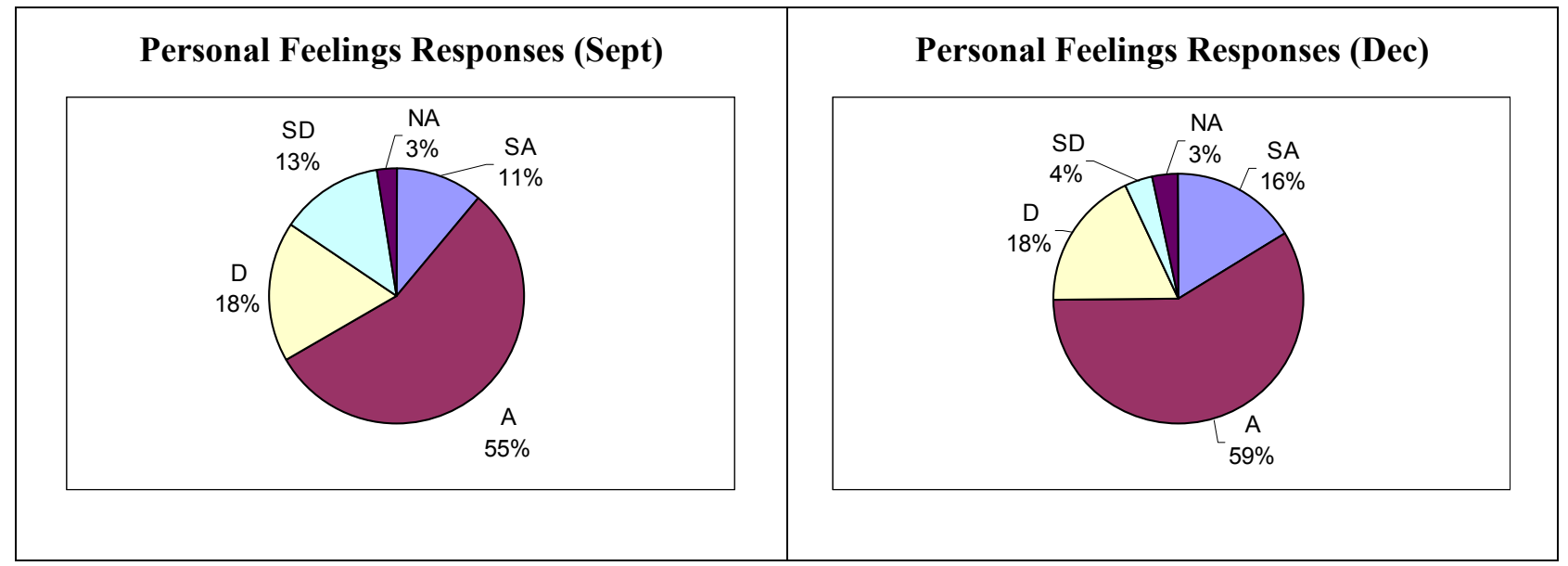

Figure 8. Responses to Personal Feelings Questions.

It should be pointed out that a second experiment was run in a different semester for the Virtual Classroom where the focus was on assessing the impact of web-based instructional modules and materials on student learning. Since this is not the focus of this paper, these results are not reported here. It is interesting to note however that in this second experiment both the control and experimental groups were required to take on the industry based projects. Unfortunately, we

Proceedings of the 2002 American Society for Engineering Education Annual Conference \& Exposition Copyright (C) 2002, American Society for Engineering Education 
did not conduct a separate study to determine if projects facilitated by the Internet were superior to traditional methods of collaborating with industry without electronic media. Our fear was this would cause a variety of logistical problems both for industry partners and students in communication and that printing and distributing industry provided statements, clarifications, and data would have been quite expensive for class lectures with enrollments of 200 students. Calculating the economic impact of hardcopy versus electronic media would be informative however. This may be investigated in future experiments. For now, we conjecture that the time and cost invested in developing electronic materials is rather high initially, but the payback period is quite reasonable as compared to the significant expense and inconvenience of hardcopy. One must also consider the high probability of lost partnerships and goodwill that may occur with frustrated collaborators and students wanting quick responses to questions.

\section{Conclusions and Future Plans}

As described earlier, the primary objective of the industry-based projects was to allow students to interact with engineers from industry to demonstrate, extend, and integrate knowledge of Engineering Economy in the solution of real-world problems. From our results, it appears that required team-based industrial projects, such as those offered by GE, improve learning by forcing students to integrate the principles of Engineering Economy during actual problem solving activities. The externally sponsored projects and team based problem solving also apparently energized the class through promotion of a peer-based learning experience. Case study activity in general may produce these desirable results. Actual final scores were significantly higher for the experimental group taking the projects than the actual final scores of the control group who did not take on the projects. Based on the results of the student questionnaire, the course achieved its goal of providing students with enhanced critical thinking skills. Students were also receptive to the use of technology as an instructional tool.

Our experience indicates that the Internet is an effective and efficient medium to reduce the logistics and costs of industry collaboration in education. As with all newly developed webbased materials, the initial start-up is higher, but the anticipated payback of these efforts is well worth the effort with reduced development and maintenance tasks over time. One can hardly imagine taking on an industry collaborative effort for large classes without affordable and easy to use resources such as the Internet.

This research has been a collaborative effort including Virginia Tech, the University of Massachusetts Amherst, and the General Electric Company. As envisioned, the virtual classroom will remain an open resource on the web that can be used by any university in teaching a first course in Engineering Economy. In addition, it is anticipated that it will serve as a continuing resource that students can return to regularly throughout their education and serve as a resource for practicing professionals. Farther reaching, this research is an integral part of a longer-term and broader vision to build an undergraduate "National Technological University" (NTU) for selected core courses in the engineering curriculum. It is anticipated that through 
computer-based learning methods utilized at the undergraduate level, higher quality core engineering courses can be offered to more students in a very cost-effective manner.

Further expansion, development, and analysis of the industry-based projects are planned. In particular, we are currently in the process of conducting analysis to discern if the same benefits to student learning and perception hold true for smaller class sizes based on data collected at the University of Massachusetts Amherst. Also, additional industry partnerships and associated problems have already been added to the web site since the initial experiment. Our plans are to continue this expansion and invite other industry partners and more universities to participate. Finally, the use of virtual student teams formed with participants from multiple universities is another interesting avenue for future experiments. An interesting question to consider is whether the Internet would facilitate and improve distributed teaming skills and problem solving. The logistics for teams may be heightened, but these are problems and skills that students will have to deal with upon graduation.

\section{Acknowledgments}

The authors gratefully acknowledge the funding received from the National Science Foundation (NSF, DUE -9952750) to support this work. Very special thanks are due to our collaborators from General Electric (GE) Industrial Systems and Pratt and Whitney who have provided projects, time, expert advice, and student mentoring.

\section{References}

1. C. Chou, "Developing Hypertext-Based Learning Courseware for Computer Networks: The Macro and Micro Stages," IEEE Transactions on Education, vol.42, no. 1, pp. 39-44, 1999.

2. D.R. Wallace and P. Mutooni, "A Comparative Evaluation of World Wide Web - Based and Classroom Teaching," Journal of Engineering Education, pp. 211-219, 1997.

3. R.C. Larson, "MIT learning Networks: An Example of Technology - Enabled Education," A white paper by Richard Larson, Director CAES, MIT, Sept 1997. http://caes.mit.edu/programs/distance.html.

4. D.R. McIntyre and F.G. Wolff, "An Experiment with WWW Interactive Learning in University Education," Computer Education, vol. 31, pp. 255-264, 1998.

5. M.K. Black, “An Industry View of Engineering Education,” Journal of Engineering Education, vol. 83, no. 1, p. 26, Jan. 1994.

6. R. Morgan, N. Kannankutty, and D. Strickland, "Future Directions for University -Based Research," $A S E E$ Prism, pp. 30-36, March 1997.

7. Terpenny, J.P., Sward, K., and Sullivan, W.G., "Virtual Classroom for Teaching the Economics of Engineering Design," Proceedings of the 2001 ASEE Conference, Albuquerque, New Mexico, June 2001.

8. Sullivan, W.G. and Terpenny, J.P., "A Virtual Classroom Experiment for Teaching the Economic Principles of Engineering Design," Proceedings of the 2001 Frontiers in Education Conference, IEEE, Reno, NV, Oct 2001.

9. "Virtual Classroom for the Economics of Engineering Design," URL: http://mielsvr2.ecs.umass.edu/virtual_econ/. 
10. "Projects in Collaboration with Industry," URL: http://mielsvr2.ecs.umass.edu/virtual_econ/projects/project_frames.htm.

11. Paterson, K.G., "Student Perception of Internet-Based Learning Tools in Environmental Engineering Education" Journal of Engineering Education, pp 295-304, 1999.

12. URL: http://www.discusware.com/discus; DISCUS.

13. Waters, R., McCracken, M. "Assessment and Evaluation in Problem- Based Learning," Proceedings of the 1997 Frontiers In Education Conference, IEEE, 1997, pp 689-693.

14. Garfield, J.B., "Beyond Testing and Grading: Using Assessment to Improve Student Learning, " Journal of Statistics Education, vol. 2, no. 1, 1994, pp. 1-11.

15. Sullivan, W.G. and Daghestani, S.F., "Multivariate Analysis of Student Performance in Large Engineering Economy Classes," Proceedings of the ASEE Annual Conference, Milwaukee, WI, June 15, 1997.

16. Sullivan, W.G. and Martin, D.G., "An Experiment in Learning Intervention for At-Risk Students in Engineering Economy," Proceedings of the ASEE Annual Conference, Seattle, WA, 1998.

\section{Biographies}

\section{JANIS P. TERPENNY}

Janis P. Terpenny is an Assistant Professor of Mechanical and Industrial Engineering at the University of Massachusetts, Amherst. Her research interests are at the intersection of engineering design and information technology with a focus on knowledge and design representation for modeling and synthesis in early design, including distributed collaboration and learning environments. She obtained her Ph.D. degree in Industrial and Systems Engineering from Virginia Polytechnic Institute and State University and has several years of industry experience with General Electric (GE) where she completed a corporate training program in information systems.

\section{WILLIAM G. SULLIVAN}

William G. Sullivan is an emeritus professor of Industrial and Systems Engineering at Virginia Polytechnic Institute and State University. He is a two-time recipient of the Eugene L. Grant Award for the best paper in The Engineering Economist. His research interests include justification of advanced manufacturing technologies, the economic principles of engineering design, and activity-based costing applied to the design process. Dr. Sullivan serves as coeditor of the Robotics and CIM Journal (Elsevier, Ltd.) and is a fellow in the Institute of Industrial Engineers. He obtained his Ph.D. in Industrial and Systems Engineering from the Georgia Institute of Technology.

\section{HARPREET SINGH}

Harpreet Singh is currently working as an engineer at Altsom Power located in Windsor, Connecticut. He received his M.S. degree in Industrial Engineering from the University of Massachusetts at Amherst in 2000. Mr. Singh did much of the initial work on the web pages for the industry-based collaborative projects.

\section{KIMBERLY SWARD}

Kimberly Sward is currently an engineer at Westinghouse Electric Company. She received a B.S. in Biomedical Engineering from Rensselaer Polytechnic Institute in 1998 and her M.S. degree in 2001 from UMass in Industrial Engineering. . Ms. Sward did most of the design and implementation of the Virtual Classroom web site, including instructional modules, on-line quizzes, and support for the industry-based projects. 